\title{
Slide Mode and Fuzzy Logic Based Powertrain Controller for the Energy Management and Battery Lifetime Extension of Series Hybrid Electric Vehicles
}

\author{
Zheng Chen ${ }^{1}$, Xi Zhang ${ }^{2}$, and Chris Chunting $\mathrm{Mi}^{3}$ \\ ${ }^{1}$ Department of Electrical and Computer Engineering, University of Michigan, zhch@umd.umich.edu \\ ${ }^{2}$ Department of Electrical and Computer Engineering, University of Michigan, braver1980@msn.com \\ ${ }^{3}$ Department of Electrical and Computer Engineering, University of Michigan, chrismi@umich.edu
}

\begin{abstract}
A control strategy was developed to improve fuel economy, enhance engine efficiency as well as extend battery cycle life in the series hybrid electric vehicle (SHEV) powertrain. The controller was based on fuzzy logic, fixedboundary-layer sliding mode controllers (FBLSMCS) and an optimized battery charge scenario. The fuzzy logic based energy management controller is developed to determine the engine power based on two inputs, battery state-of-charge (SOC) and vehicle power demand. The goal of the fuzzy logic based controller is to enhance the engine and battery operation efficiency and at the mean time, extend battery life. An appropriate battery charge scenario is designed to remove surge charge current, and avoid persistently-high charge power, which are positive factors to the battery lifetime extension. Besides, two robust FBLSMCs against uncertain disturbances are configured in the powertrain control system, responsible for engine speed control and engine torque control, respectively. Simulation results are obtained for comparison between the proposed and conventional powertrain control schemes. Through these simulations, the effectiveness and superiority of the proposed powertrain control strategy are validated.
\end{abstract}

\section{Keywords}

series hybrid electric vehicle, fuzzy logic, fixed-boundary-layer sliding mode controllers, battery charge scenario state of charge, life cycle

\section{INTRODUCTION}

Hybrid electric vehicles (HEVs), combining a conventional propulsion system with an energy storage system (ESS) and one or more electric machines, have attracted more and more attention due to their higher fuel efficiency and lower emissions [Kim et al., 2008; Baisden and Emadi, 2004; Prokhorov, 2007]. They are mainly classified into three classes: series HEV (SHEV), parallel HEV, and series-parallel (or complex) HEV vehicle. In particular, the SHEV architecture has been extensively used in the development of a new class of plugin HEV (PHEV), extended ranged electric vehicle (EREV) which offers the capability of being driven electrically.

In a SHEV, the electric power as the only propulsion power comes from the ESS and the engine/generator unit that converts the energy from fuel into electricity [Barsli et al., 2002; He and Yang, 2006; Syed et al., 2006]. The simple and decoupled mechanical structure in SHEV brings many advantages although there are some unsatisfactory characteristics, such as the requirement of larger power capacity for the traction motor, an additional generator than a parallel HEV.
By using the traction motor for propulsion, the operating noises can be reduced, which provides the stealth function for certain military applications. In addition, high efficiency operation of the engine can be obtained with optimization of engine control.

Recently, many researchers have been focusing on the various control issues of the SHEV powertrain. Plsu and Rizzoni [2005] introduced a modified instantaneous equivalent consumption minimization strategy (ECMS) into a SHEV powertrain control system. A simulated annealing (SA) algorithm was proposed to optimize the operational parameters for SHEV fuel economy and emissions [Wang et al., 2008]. Barsali et al. [2004] presented a knowledge-based control strategy for fuel consumption minimization using information of the engine efficiency map, vehicle battery behavior and some overall parameters characterizing the expected trip. A power-flow management algorithm considering a normal operation mode and an electric vehicle (EV) operation mode appeared in [Yoo et al., 2008]. However, these SHEV powertrain control strategies fail to sufficiently address the highly nonlinear parameter variations and sudden external disturbances during the vehicle operation.

There are two typical energy management methods for SHEVs: Thermostat control strategy and power follower strategy. The thermostat control strategy works similar to a thermostat device, which uses the 
fuel converter as follows: To maintain charge in the battery, the fuel converter turns on when the SOC reaches the low limit. The fuel converter turns off when the SOC reaches the high limit. The fuel converter operates at the most efficient speed and torque level. The power follower strategy is much more complicated than the thermostat strategy. It defines the engine on and engine off zone, however, it mainly uses the engine, which could work in the optimal area, the redundant or insufficient energy will charge to or discharge from the battery [NREL, 2002]. The power follower strategy only use the battery as the supplement energy source and it doesn't include the energy distribution between two sources: engine and battery. So designing an intelligent energy management algorithm becomes necessary which could determine the each source's output based on the vehicle status, such as acceleration, vehicle velocity, battery SOC, and engine speed, etc. Fuzzy logic is an innovative technology that enhances conventional system design with engineering expertise. The use of fuzzy logic can help circumvent the need for rigorous mathematical modeling. For series HEV, fuzzy logic could deal with the problem without very complicated tools and the nonlinear equation [Eren et al., 2009; Gao et al., 2008; Chen et al., 2008; Hajimiri and Salmasi, 2006, 2008]. It will accomplish the whole procedure through several steps. First, it needs to define the membership of each key status: power demand, vehicle velocity and SOC as inputs and power ratio, the power distribution between the engine and the battery, as outputs. Then it defines the rules based on experience or mathematical computing, and at last it finishes the defuzzification based on the output membership function.

Once the power ratio is decided by the fuzzy controller, the engine needs to be controlled to operate in the most efficiency area. For this purpose, sliding mode control (SMC) is introduced in this paper to control the operation of the engine. SMC is an efficient tool to control complex high-order dynamic plants operating under uncertain conditions due to the order reduction property and low sensitivity to disturbances and plant parameter variations [Proca et al., 2002; Jackson and Shtessel, 1998; Kachroo and Tornizuka]. Consequently, it is very suitable for automotive applications. The chattering-free fixed-boundary-layer sliding mode controller (FBLSC) is utilized with the advantage that the boundary width is kept fixed so that the area where the system trajectories are attracted toward the boundary will not vary unexpectedly at all. To locate the engine operation in the optimal efficiency region, two proposed FBLSCs, responsible for engine speed and torque respectively, work together due to the simultaneous speed and torque magnitude constraints in such an area. As a result, the strong system robustness can be achieved against the nonlinear parameter variations and external disturbances.

A third aspect to be studied in this paper is the battery life extension through optimized charge scenarios. The battery technology attracts more and more concerns from researchers involved in $\mathrm{HEV}$ research since it is the key technology and bottleneck of the future HEVs and PHEVs [Yao et al., 2007]. Considerable battery manufacturers dedicate themselves to the breakthrough of barriers on the cost, size, life and energy density of batteries [Martha et al., 2006; Ozaki et al., 2006; Richey, 2004]. Unfortunately, researchers so far have not been able to achieve systematical solutions for battery lifetime extension under the present battery technology. In fact, it is very difficult to predict the battery lifetime by using chemical or electrical variables and to test the batteries for the full range of applications in which batteries are used. However, it's possible to analyze some stress factors which induce aging and influence the rate of aging [Svoboda et al., 2007]. Consequently, comparison between two aging processes with a couple of different stress factors (e.g. $\mathrm{SOC}$, charge rate, temperature, etc.) is possible as long as other operating conditions are similar.

The battery charge current is determined by the energy management controller, as well as the actual engine output power during the engine operation process. In general, the battery charge/discharge current is chaotic and varies rapidly, and surge current exists, which tend to impact the battery life [Wenzl et al., 2005]. In the meantime, the battery SOC usually cannot reach a high level in a short time while the low SOC is unfavorable to the battery durability in a long term. To solve the above problems, a smooth battery charge curve of current vs SOC is needed, and this curve has to be ordinate-large at low SOC so that the SOC can increase as quickly as possible. Additionally, persistently-high power should be relatively avoided because it has potential negative influence to battery life [Wenzl et al., 2005]. Considering these aspects, this paper presents an ellipse-like-based battery charge scenario. In other words, the curve of the charge current vs battery SOC is like an ellipse. When the engine starts, the battery keeps charging at a high rate from the low SOC level, and its SOC increases fast. The charge current gradually drops to zero when the SOC approaches the predetermined maximum level. In this case, an average high SOC can be guaranteed while the persistently-high power can also be avoided. Most importantly, the chaotic and fast-variable current almost disappears, which is very good for battery lifetime extension. Nevertheless, it has to be noted that in the proposed powertrain control method, the power of 


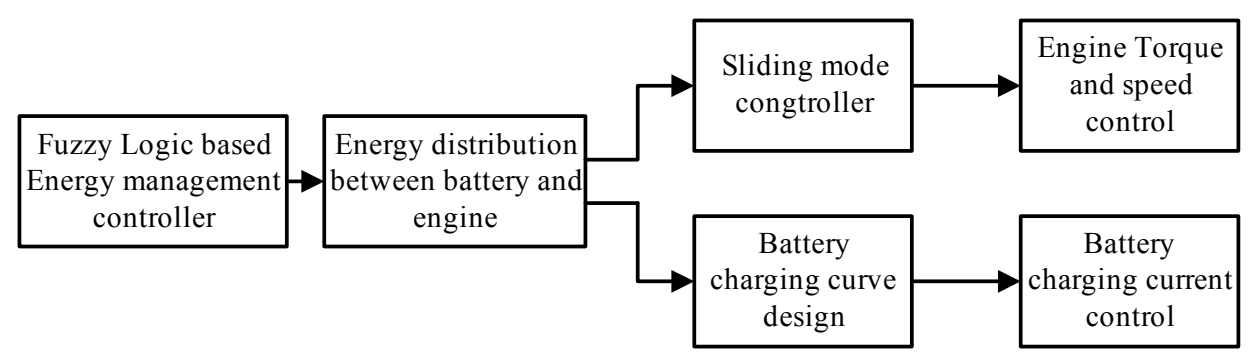

Fig. 1 The novel powertrain controller for SHEV

the engine during its operation is determined by power requirements of the battery and traction motor, which is an inverse power derivation process compared to that used in other SHEV powertrain control strategies. The novel powertrain controller proposed in the paper and its specific function for each part is shown in Figure 1.

Integration of the proposed fuzzy logic control algorithms, FBLSCs and ellipse-like-based battery charge scenario is implemented by modifying the original SHEV model in the modeling tool Advanced Vehicle Simulator (ADVISOR). Simulation results verify that the proposed design strategy of SHEV powertrain controllers is valid and more efficient compared with the conventional methodology.

\section{SYSTEM CONFIGURATION AND DRIVE CYCLE SELECTION}

\subsection{Powertrain structure and component specifica- tions}

The frame of the studied SHEV powertrain is shown in Figure 2. Consequently, the gasoline engine is a Geo Metro 1.0 L SI engine with maximum power of $41 \mathrm{~kW}$ at $5700 \mathrm{rpm}$. The speed and torque independent permanent magnet synchronous generator (PMSG) generates rated $41 \mathrm{~kW}$ output power with approximately highest $95 \%$ efficiency. An AC induction motor (IM), output power rated $75 \mathrm{~kW}$ power with $92 \%$ efficiency, acts as the traction motor for the vehicle propulsion. The ESS consists of 15 Hawker Genesis Lead Acid Battery in series. The capacity and nominal voltage of each cell are $12 \mathrm{Ah}$ and $12 \mathrm{~V}$, respectively.

\subsection{Drive cycles}

Driving cycles are defined as test cycles that are used to standardize the evaluation of vehicle fuel economy and emissions. Driving cycles are speed-time sequences that represent the traffic conditions and driving behavior in a specific area. Driving patterns may vary from city to city and from area to area; therefore, the use of a driving cycle obtained for certain cities or countries is not necessarily applicable to other cities.

To evaluate fuel consumption and emissions in this study, the Environment Protection Agency (EPA) defined Urban Dynamometer Driving Schedule (UDDS) was used. The UDDS is a typical "city test" cycle and represents city driving conditions. It is used for light duty vehicle testing.

\section{FUZZY LOGIC CONTROL ALGORITHM}

The fuzzy logic control algorithm evolves from forementioned power follower strategy, for the power follower strategy is only a rule based strategy. The power follower strategy doesn't consider the optimal issue in the real system, only the SOC is a fixed target. Some engine operating points could be fetched based on the engine efficiency map, whose values are suboptimal. It needs to be further optimized. Fuzzy logic control has been applied as an effective control method in various fields. The advantages of this strategy are its inherent robustness and ability to handle both non-linearity and linguistic knowledge. It also has immunity to imprecise measurements and to component variability. The robust property of fuzzy logic controller enables the HEV to be operated with the improved battery charge balance, regardless of various disturbances. Therefore,

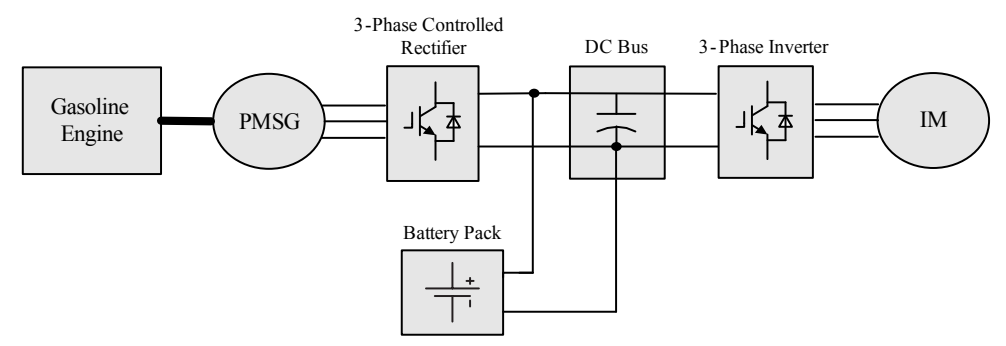

Fig. 2 Powertrain structure of the SHEV studied in this paper 


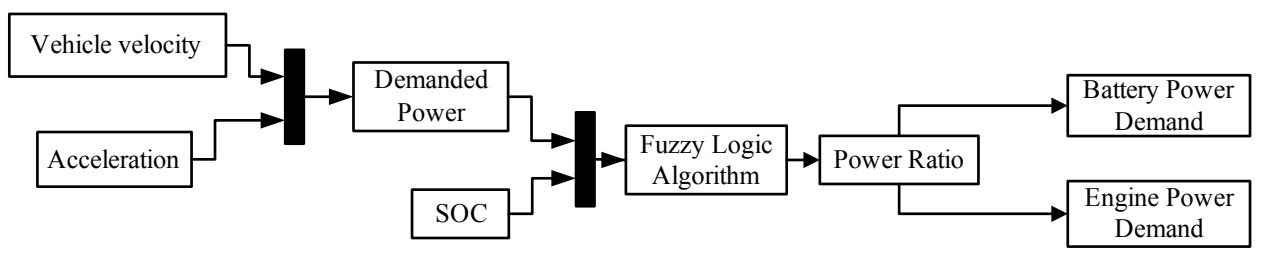

Fig. 3 Fuzzy logic energy management structure

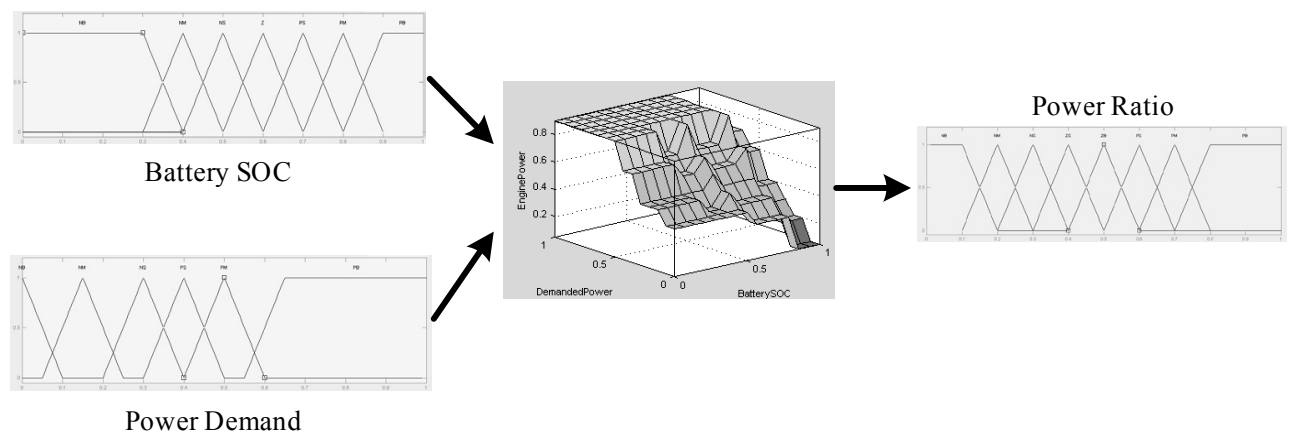

Fig. 4 The Fuzzy logic rules and each variant membership function

fuzzy logic controller is a suitable method for SHEV energy control characterized by its non-linearity and uncertainties.

In this study, the fuzzy logic controller (FLC) is a Mamdani type fuzzy system as shown in Figure 3. The system demanded power and SOC at each time are considered the inputs of the FLC; the output is also the membership function which represents the power ratio. The whole structure of fuzzy logic energy system is shown in Figure 3. The demanded power which was calculated from the vehicle velocity and acceleration is first estimated, and then classified into $\{N B, N M, N S, P S, P M, P B\}$ which represent the vehicle power demand from minimum value to maximum value, battery SOC is classified into $\{N B, N M, N S, Z$, $P S, P M, P B\}$, which could reflect SOC from 0 to 1 , and the output ratio is classified into $\{N B, N M, N S$, $Z S, Z B, P S, P M, P B\}$, as shown in Figure 4.

The whole control rules library consists of 42 If-else rules, shown in the middle of Figure 4.

\section{ESTABLISHMENT OF SLIDING MODE CONTROL}

The vehicle operation process is highly nonlinear, resulting in highly-nonlinear and uncertain engine dynamics. Simple control models cannot handle complicated engine dynamics well because they need accurate information and lack of robustness that is essential to the control objective. The sliding mode control (SMC) is well known for its advantages in providing a systematic approach to the problem of maintaining stability and consistent performance facing modeling imprecision. In SMC, the system trajectory is maintained to stay on the sliding surface for subsequent time once it is driven onto this surface. The imperfect implementation of the control switching leads to chattering, which is a major drawback of the SMC. The advantages of the fixed-boundarylayer sliding mode controller (FBLSMC) are that, not only chattering phenomenon is removed, but also the boundary width is kept fixed so that the area where the

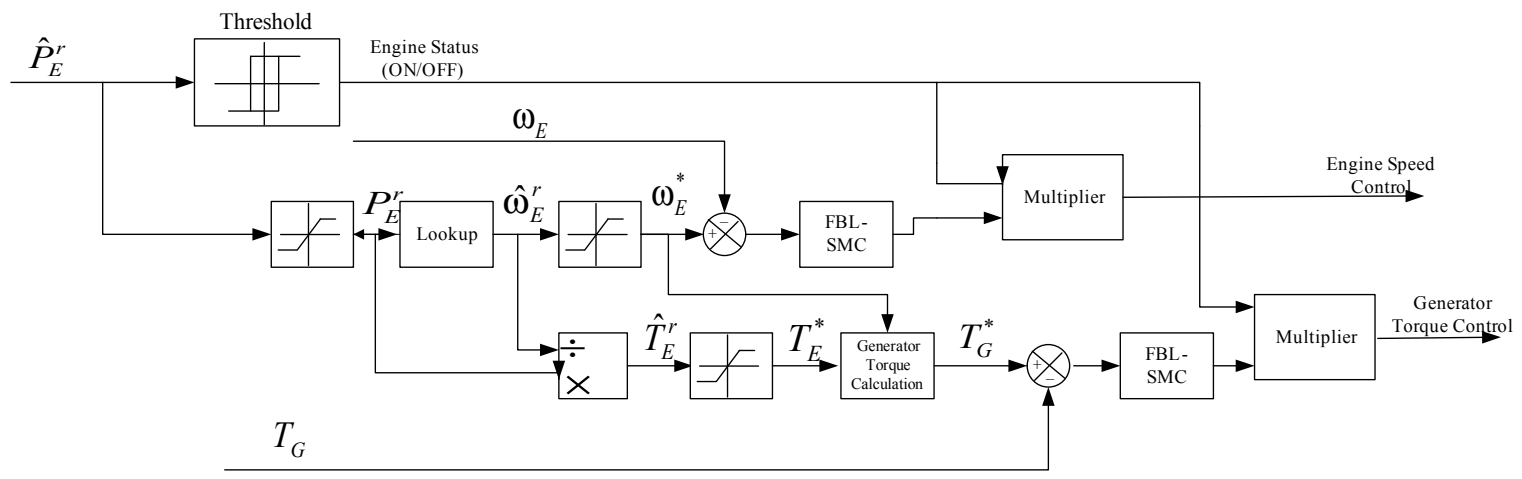

Fig. 5 Block schematic of the proposed SHEV powertrain control strategy 
trajectories are attracted toward the boundary is not changed avoiding the instability of normal chatteringfree sliding mode controllers. Therefore, the FBLSMC strategy is employed in this study as an effective tool for enhancement of engine efficiency to locate the engine speed and torque into the optimum area.

Besides, an ellipse-like-based battery charge current curve (current vs SOC) is decided considering the fore-mentioned advantages. Based on the expected engine operation curve and optimum region definition, the desired engine speed and torque can be obtained. As a matter of fact, the engine torque depends on the generator torque which is adjusted by the PWM signals for the controlled rectifier. So the objectives for powertrain control change to controlling the engine speed and generator torque to constrain the engine operation in the optimum region. Two FBLSMCs respectively responsible for the engine speed and generator torque are utilized against the parameter variations, external disturbances, and highly-nonlinear system dynamics. The whole control process is shown in Figure 5. The variables in this figure are defined as follows: $\hat{P}_{E}^{r}$, original required engine power; $P_{E}^{r}$ , required engine power with thresholds; $\hat{\omega}_{E}^{r}$, original required engine speed; $\omega_{E}^{*}$, required engine speed with thresholds; $\omega_{E}$, real engine speed; $\hat{T}_{E}^{r}$, original required engine torque; $T_{E}^{*}$, required engine torque with thresholds; $T_{G}^{*}$, final required generator torque; $T_{G}$, real generator torque.

The state equation of the engine is expressed as:

$$
\frac{\mathrm{d} \omega_{E}}{\mathrm{~d} t}=\frac{1}{J_{s}} u f\left(\omega_{E}\right)-\frac{1}{n J_{s}} T_{G}
$$

where $f\left(\omega_{E}\right)$ is the maximum engine torque at a certain $\omega_{E} ; n$ is engine/generator speed ratio $\approx 1 ; J_{S}$ is the inertia of the engine/generator set; $u$ represents the engine throttle angle and acts as a control variable for the engine speed FBLSMC.

The state of the generator employed in the SHEV is described as:

$\frac{\mathrm{d} i_{q}}{\mathrm{~d} t}=-\frac{R}{L} i_{q}-\omega_{G} i_{d}+\frac{\omega_{G}}{L} \lambda_{m}-\frac{u_{q}}{L}$

$\frac{\mathrm{d} i_{d}}{\mathrm{~d} t}=-\frac{R}{L} i_{d}+\omega_{G} i_{q}-\frac{u_{d}}{L}$

$T_{G}=K_{t r q} i_{q}$

where $i_{d}, i_{q}$ are direct- and quadrature- axis stator currents, respectively; $L_{d}, L_{q}$ are direct- and quadratureaxis inductances, respectively; $\lambda_{m}$ is amplitude of the flux linkages established by the permanent magnet; $R$ is stator resistance; $\omega_{G} \approx \omega_{E}$ is generator speed; $K_{t r q}$ is a torque constant; $u_{d}, u_{q}$, considered as control variables for the generator torque FBLSLC as well as the engine torque control, represent direct- and quadrature- axis stator voltages, respectively.

\section{SIMULATION RESULTS}

Advanced Vehicle Simulator (ADVISOR) is employed as the simulation tool in this study. The proposed powertrain control strategy is embedded in the modified SHEV model originated from ADVISOR as shown in Figure 6. The engine operation is shown in Figure 7 and Figure 8 for the classical "power follower" strategy and the proposed strategy, respectively.

From the comparison between Figure 7 and Figure 8, it is clear that most engine operation points using the

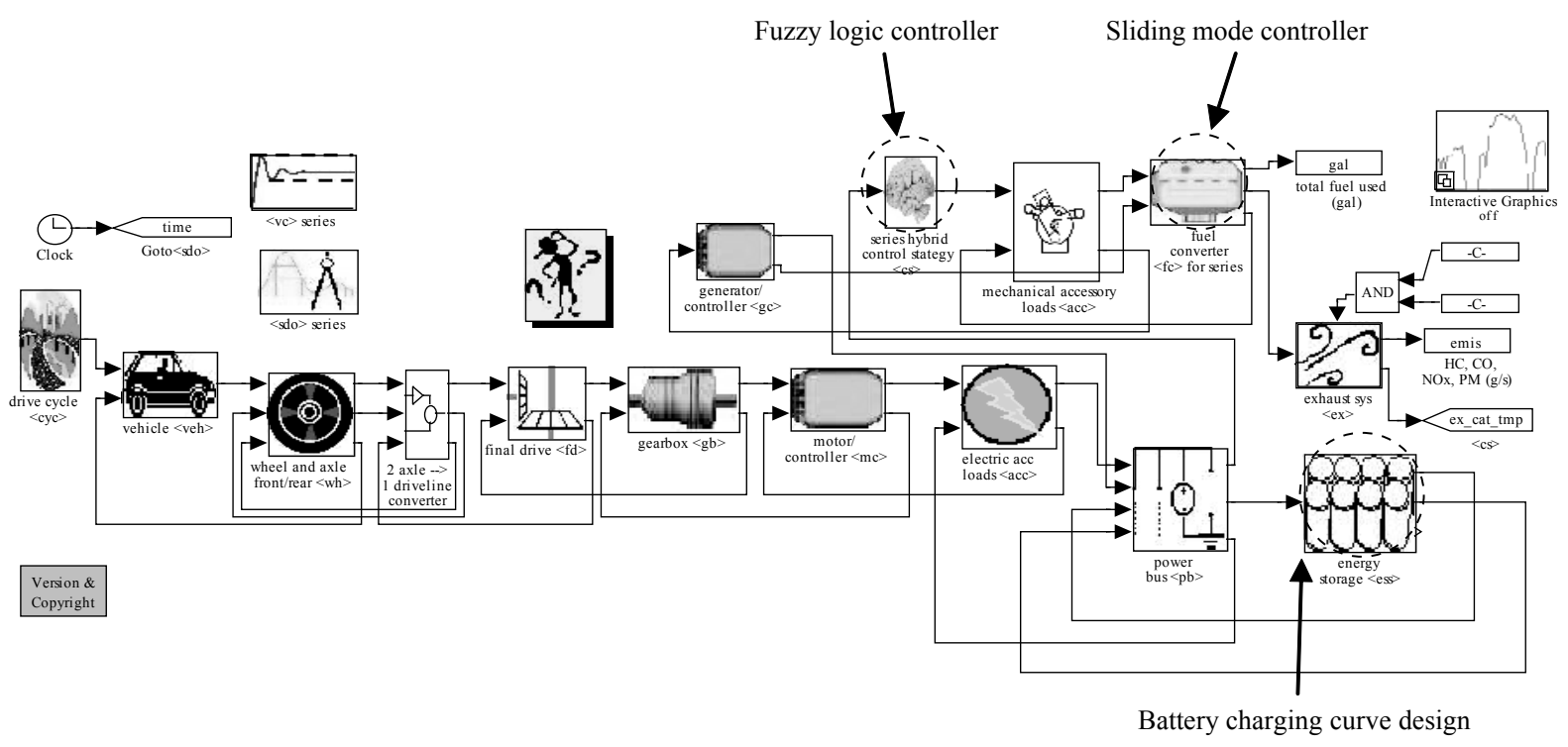

Fig. 6 Modified SHEV model for algorithm implementation 


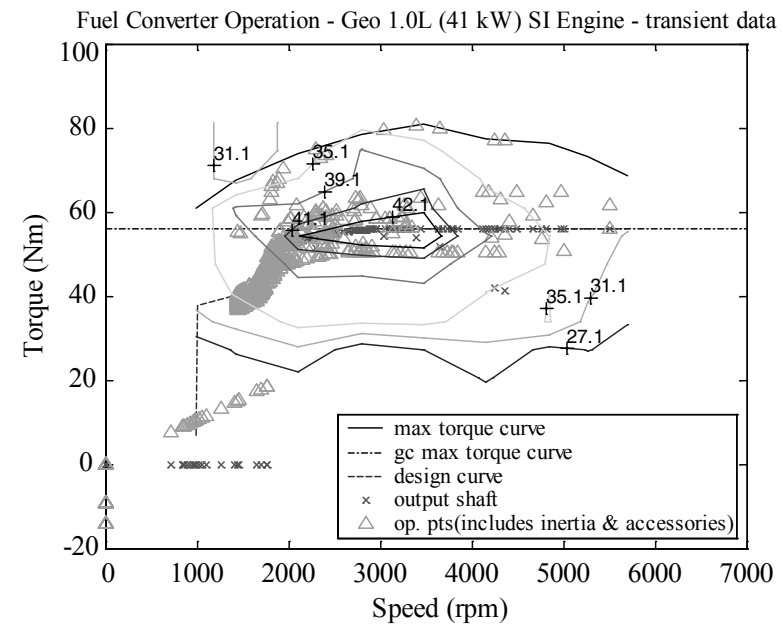

Fig. 7 Engine operation during UDDS (conventional method)

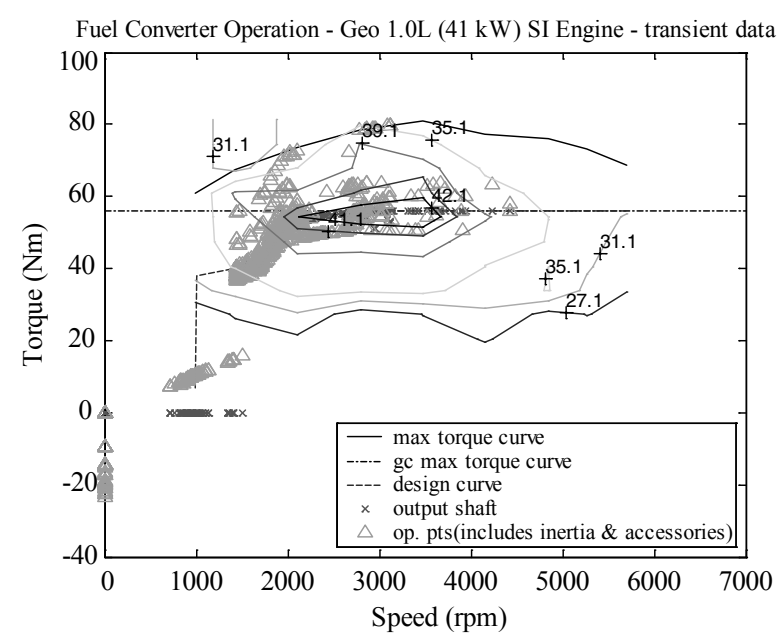

Fig. 8 Engine operation during UDDS (proposed method)

proposed method concentrate in the optimal area of the engine efficiency map while the majority of the engine operation points using the conventional method are located beyond such an area. In other words, the proposed method can boost the engine efficiency as a result. Some partial battery charging curve is shown in Figure 9 and Figure 10 respectively. The charging current looks like partial ellipse in Figure 10 which realizes the charging demand.

The miles per gallon (MPG) which could represent the fuel consumption based on the novel control algorithm is 44.5 compared with the original value 42.9 , with an improvement of $3.73 \%$.

\section{CONCLUSION}

The fuzzy Logic control algorithm is applied to manage the power distribution between engine and battery of a SHEV. The fuzzy logic based energy manage-

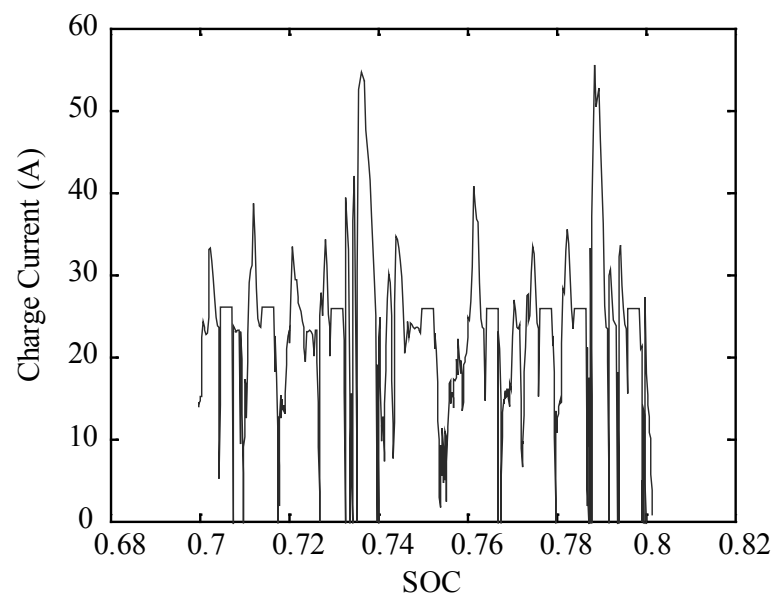

Fig. 9 Battery charging curve (no current control)

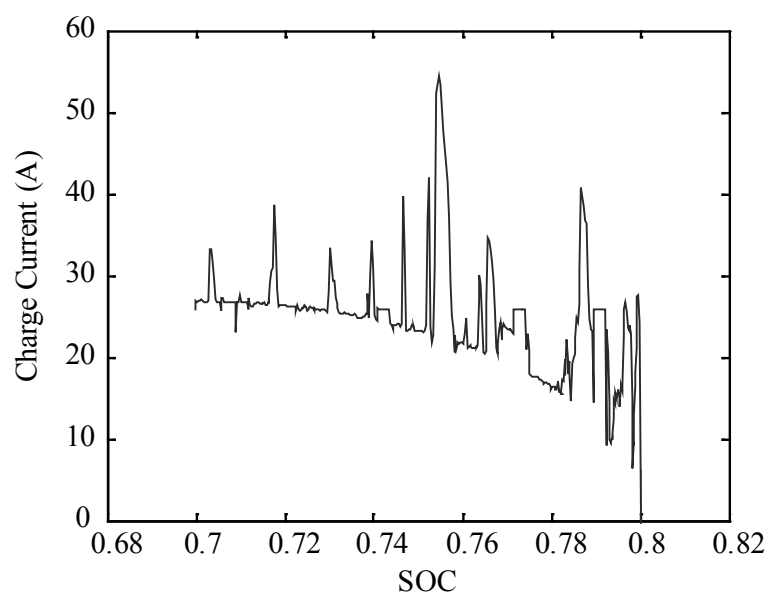

Fig. 10 Battery charging curve (charging current control)

ment controller can optimize the power distribution between the engine and the battery based on the battery SOC and the vehicle power demand. Two fixedboundary-layer sliding mode controllers (FBLSMCs) are developed for the powertrain controller design in the SHEV for the purpose of efficiency enhancement and battery lifetime extension. The two FBLSMCs are in charge of the speed control and torque control for the engine, respectively, against the parameter variations and disturbances. A battery charge scenario avoiding the chaotic current is designed for battery life extension with the consideration of some stress factors. The effectiveness and superiority of the proposed SHEV powertrain control strategy are validated through simulation conducted in Advisor tool.

\section{Acknowledgement}

The authors would like to acknowledge AVL for the support of the Advisor software which is used in the study of this paper. 


\section{References}

Barsli, S., M. Ceraolo, and A. Possenti, Techniques to control the electricity generation in a series hybrid electrical vehicle, IEEE Transactions on Energy Conversion, Vol. 17, No. 2, 260-266, 2002.

Baisden, A. C., and A. Emadi, Advisor-based model of a battery and an ultra-capacitor energy source for hybrid electric vehicles, IEEE Transactions on Vehicular Technology, Vol. 53, No. 1, 199-206, 2004.

Barsali, S., C. Miiulli, and A. Possenti, A control strategy to minimize fuel consumption of series hybrid electric vehicles, IEEE Transactions on Energy Conversion, Vol. 19, No. 1, 187-195, 2004.

Chen, J., and Y. Li, Simultaneous optimisation of fuel consumption and emissions for a parallel hybrid electric SUV using fuzzy logic control, International Journal of Vehicle Design, Vol. 46, No. 2, 204218, 2008.

Eren, Y., O. Erdinc, H. Gorgun, M. Uzunoglu, and B. Vural, A fuzzy logic based supervisory controller for an FC/UC hybrid vehicular power system, International Journal of Hydrogen Energy, Vol. 34, 8681-8694, 2009.

Gao, D., Z. Jin, Q. Lu, Energy management strategy based on fuzzy logic for a fuel cell hybrid bus, Vol. 185, 311-317, Journal of Power Sources, 2008.

Hajimiri, M. H., F. R. Salmasi, A fuzzy energy management strategy for series hybrid electric vehicle with predictive control and durability extension of the battery, IEEE Conference on Electric and Hybrid Vehicles, 1-5, 2006.

Hajimiri, M. H., and F. R. Salmasi, A predictive and battery protective control strategy for series HEV, Journal of Asian Electric Vehicles, Vol. 6, No. 2, 1159-1165, 2008.

He, B., and M. Yang, Robust LPV control of diesel auxiliary power unit for series hybrid electric vehicles, IEEE Transactions on Power Electronics, Vol. 21, No. 3, 791-798, 2006.

Jackson, M. E., and Y. B. Shtessel, Sliding mode thermal control system for space station furnace facility, IEEE Transactions on Control System Technology, Vol. 6, No. 5, 612-622, 1998.

Kachroo, P., and M. Tornizuka, Chattering reduction and error convergence in the sliding-mode control of a class of nonlinear systems, IEEE Transactions on Automatic Control, Vol. 41, No. 7, 1063-1068, 1996.

Kim, D., S. Hwang, and H. Kim, Vehicle stability enhancement of four-wheel-drive hybrid electric vehicle using rear motor control, IEEE Transactions on Vehicular Technology, Vol. 57, No. 2, 727-735, 2008.

Martha, S. K., B. Hariprakash, S. A. Gaffoor, D. C.
Trivedi, and A. K. Shukla, A low-cost lead-acid battery with high specific-energy, Journal of Chemical Sciences, Vol. 118, No. 1, 93-98, 2006.

NREL, Software- ADvanced VehIcle SimulatOR (ADVISOR) 2002, help: Series Control Strategy.

Ozaki, T., H. B. Yang, T. Iwaki, S. Tanase, T. Sakai, H. Fukunaga, N. Matsumoto, Y. Katayama, T. Tanaka, T. Kishimoto, and M. Kuzuhara, Development of Mg-containing $\mathrm{MmNi}_{5}$-based alloys for low-cost and high-power Ni-MH battery, Journal of Alloys and Compounds, Vol. 408-412, 294-300, 2006.

Plsu, P., and G. Rizzoni, A supervisory control strategy for series hybrid electric vehicles with two energy storage systems, Proceedings of IEEE Vehic. Power and Propulsion Conference, 65-72, 2005.

Proca, A., A. Keyhani, V. Utkin, and J. Miller, Discrete time sliding mode, continuous time sliding mode and vector control of induction motors, International Journal of Control, Vol. 75, No. 12, 901909, 2002.

Prokhorov, D., Toyota prius HEV neurocontrol, Proceedings of International Joint Conference on Neural Networks, 2129-2134, 2007.

Richey, S., Flywheel technology helps life spring eternal for battery systems, EC and M: Electrical Construction and Maintenance, Vol. 103, No. 4, 34+3638, 2004.

Svoboda, V., H. Wenzl, R. Kaiser, A. Jossen, I. Baring-Gould, J. Manwell, P. Lundsager, H. Bindner, T. Cronin, P. Norgard, A. Ruddell, A. Perujo, K. Douglas, C. Rodrigues, A. Joyce, S. Tselepis, N. Borg, F. Nieuwenhout, N. Wilmot, F. Mattera, D. U. Sauer, Operating conditions of batteries in off-grid renewable energy systems, Solar Energy, Vol. 81, No. 11, 1409-1425, 2007.

Syed, F. U., M. L. Kuang, J. Czubay, and H. Ying, Derivation and experimental validation of a powersplit hybrid electric vehicle model, IEEE Transactions on Vehicular Technology, Vol. 55, No. 6, 1731-1747, 2006.

Wang, Z., B. Huang, Y. Xu, and W. Li, Optimization of series hybrid electric vehicle operational parameters by simulated annealing algorithm, Proceedings of IEEE International Conference on Control \& Automation, 1536-1541, 2008.

Wenzl, H., I. B. Gould, R. Kaiser, B. Y. Liaw, P. Lundsager, J. Manwell, A. Ruddell, and V. Svoboda, Life prediction of batteries for selecting the technically most suitable and cost effective battery, Journal of Power Sources, Vol. 144, No. 2, 373-384, 2005.

Yao, M., K. Okuno, T. Iwaki, S. Tanase, K. Harada, M. Kato, K. Emura, and T. Sakai, High-power nickel/ metal-hydride battery using new micronetwork substrate: discharge rate capability and cycle-life 
performance, Journal of Power Sources, Vol. 171, No. 2, 1033-1039, 2007.

Yoo, H., S. K. Sul, Y. Park, and J. Jeong, System integration and power-flow management for a series hybrid electric vehicle using supercapacitor and batteries, IEEE Transactions on Industry Applications, Vol. 44, No. 1, 108-114, 2008.

(Received November 10, 2010; accepted November 18, 2010) 